J. Dairy Sci. 95:7105-7114

http://dx.doi.org/10.3168/jds.2012-5627

(C) American Dairy Science Association ${ }^{\circledR}, 2012$.

\title{
Relationship between bacteriological findings in the second and fourth weeks postpartum and uterine infection in dairy cows considering bacteriological results
}

\author{
A. Werner, V. Suthar, J. Plöntzke, and W. Heuwieser ${ }^{1}$ \\ Clinic for Animal Reproduction, Faculty of Veterinary Medicine, Freie Universität Berlin, Königsweg 65, Haus 27, 14163 Berlin, Germany
}

\begin{abstract}
The uterine lumen in early postpartum dairy cows is contaminated with different bacteria. The most relevant uterine pathogens are Escherichia coli and Trueperella pyogenes. Prevalence of $\alpha$-hemolytic streptococci and coagulase-negative staphylococci (CNS) is also high; however, these pathogens are considered opportunistic. The overall objective of this study was to investigate effects of the intrauterine presence of $E$. coli, T. pyogenes, $\alpha$-hemolytic streptococci, or CNS at $10 \pm 1 \mathrm{~d}$ in milk (DIM) on the type of bacteria $2 \mathrm{wk}$ later and their influence on uterine infections and subsequent reproductive performance. Furthermore, we set out to quantify 2 relevant methodological factors (i.e., laboratory and sampling instrument). Bacteriological samples were collected at $10 \pm 1$ and $24 \pm 1$ DIM from the uterine lumen using a cytobrush (CB). Vaginal mucus was classified by vaginoscopy. In a subsample, bacteriological results of 3 different laboratories and of CB and cotton swabs (CS) were compared. Samples of uterine discharge were collected at $10 \pm 1$ DIM and bacteriological samples were taken using $\mathrm{CB}$ and CS. Bacteria were identified and bacterial growth quantified on a 4-point scale. Animals infected with E. coli or T. pyogenes at $10 \pm 1$ DIM had a higher risk for an infection with the same bacterial species at $24 \pm 1$ DIM [E. coli relative risk $(\mathrm{RR})=3.7$ and $T$. pyogenes $\mathrm{RR}=2.9$ ] Moreover, the risk of being diagnosed with abnormal vaginal discharge at $24 \pm 1$ DIM increased in cows with E. $\operatorname{coli}(\mathrm{RR}=1.7)$ or $T$. pyogenes $(\mathrm{RR}=1.7)$ at $10 \pm$ 1 DIM. Uterine infection with $\alpha$-hemolytic streptococci or CNS did not increase the risk of an infection with $T$. pyogenes or $E$. coli or abnormal vaginal discharge 2 wk later. Cows with E. coli at $10 \pm 1$ DIM or T. pyogenes at $24 \pm 1$ DIM had greater days to first artificial insemination than cows positive for the 3 remaining bacterial species. Cows with T. pyogenes at $10 \pm 1$ DIM
\end{abstract}

Received April 16, 2012.

Accepted August 4, 2012.

${ }^{1}$ Corresponding author: w.heuwieser@fu-berlin.de had more days to pregnancy and more cows were culled when positive for E. coli at $10 \pm 1$ DIM. Agreement of bacteriological results of 3 different laboratories were significant for laboratory $\mathrm{A}+\mathrm{B}$ and $\mathrm{A}+\mathrm{C}$ for the $\mathrm{CB}$ and CS. The highest agreement considering the bacterial species was for $E$. coli. All results for laboratory A $+\mathrm{B}$ and $\mathrm{A}+\mathrm{C}$ for the $\mathrm{CB}$ and $\mathrm{CS}$ were significant. The results generated from samples collected with $\mathrm{CB}$ agreed nicely with those from CS from each laboratory (laboratory A: 250/272; laboratory B: 264/272; laboratory C: $253 / 272$ ).

Key words: dairy cow, bacteriology, uterine infection, cytobrush

\section{INTRODUCTION}

The uterine lumen in early postpartum dairy cows is commonly contaminated with different bacteria (Bondurant, 1999; Földi et al., 2006; Sheldon et al., 2008). Calving difficulties, retained fetal membranes, and manual manipulations increase the risk of uterine infection (Lewis, 1997; Sheldon and Dobson, 2004; Potter et al., 2010). Most cows eliminate the bacterial contamination in the first $2 \mathrm{wk}$ after calving (Bondurant, 1999; LeBlanc et al., 2002). Persisting infections can lead to puerperal metritis (PM) or clinical endometritis (CE; Földi et al., 2006). Puerperal metritis is defined by an abnormally enlarged uterus and a fetid, watery, red-brown uterine discharge and, in the acute form, is associated with signs of systemic illness and fever $>39.5^{\circ} \mathrm{C}$ within 21 DIM (Sheldon et al., 2006). Clinical endometritis can be defined as purulent uterine discharge detectable in the vagina after 21 DIM or mucopurulent discharge detectable in the vagina after 26 DIM (Sheldon et al., 2006). Bacterial uterine infections have been shown to negatively affect uterine and ovarian function and fertility (Miller et al., 2007; Williams et al., 2007; Kaneko and Kawakami, 2008). Bacterial species that cause PM or CE (Elliott et al., 1968; Bonnett et al., 1991; Petit et al., 2009) were classified according their expected pathogenic potential and arranged in a table based on recent studies by Williams et 
al. (2005) into recognized uterine pathogens associated with uterine endometrial lesions (Trueperella pyogenes, Escherichia coli, Fusobacterium necrophorum, and Prevotella melaninogenica); potential pathogens frequently isolated from the bovine uterine lumen and cases of endometritis, but not commonly associated with uterine lesions; and opportunist contaminants transiently isolated from the uterine lumen and not associated with endometritis.

Although E. coli is widespread in the environment, specific E. coli strains from cows with uterine disease have been isolated (Sheldon et al., 2010). These endometrial pathogenic E. coli have been shown to be more adherent and invasive for endometrial epithelial and stromal cells compared with $E$. coli isolated from the uterus of clinically unaffected animals (Sheldon et al., 2010). Such pathogenic strains cause diseases of mucosal surfaces such as metritis or clinical endometritis in the bovine genital tract.

Trueperella pyogenes is often isolated from the uterine lumen of cows affected with PM or CE (Bonnett et al., 1991; Huszenicza et al., 1999) and synergistically affects the infection with gram-negative anaerobes such as F. necrophorum and P. melaninogenica (Williams et al., 2005; Földi et al., 2006; Sheldon et al., 2009b). The presence of $T$. pyogenes correlates with an increased risk for abnormal vaginal discharge or fetid odor (Williams et al., 2005) and elevated amount of PMNL in the epithelium and stratum compactum (Bonnett et al., 1991; Azawi et al., 2008).

Coagulase-negative staphylococci and $\alpha$-hemolytic streptococci were frequently isolated in the first weeks postpartum from the uterine lumen of dairy cows (Williams et al., 2005). The presence of $\alpha$-hemolytic streptococci was negatively correlated with the risk of abnormal vaginal mucus (Huszenicza et al., 1999; Williams et al., 2005) and both bacteria are considered to be opportunists. No information is available, however, about whether they have the potential to pave the way for infections with pathogenic bacteria later in the postpartum period.

In studies investigating uterine infections, cotton swabs (CS) were used for bacterial examinations of the vagina, cervix, or uterine lumen of cows (Williams et al., 2005; Azawi et al., 2008; Petit et al., 2009), bitches, or mares (Kasimanickam et al., 2005). A technique utilizing a cytobrush (CB) has been evaluated for the collection of cervical and endometrial cells in human medicine (Koonings et al., 1992) and was modified to collect endometrial cells in cows (Kasimanickam et al., 2005; Kaufmann et al., 2009; Plöntzke et al., 2011). This method has provided relevant insights on the association of the number of PMNL and reproductive performance but was never validated for collection of bacteriological samples.

The overall objective of this study was to investigate relationships between E. coli, T. pyogenes, a-hemolytic streptococci, and CNS at $10 \pm 1$ DIM and their presence and effect on each other or uterine infections $2 \mathrm{wk}$ later. Furthermore, we set out to evaluate 2 relevant methodological factors (i.e., laboratory and sampling instrument).

Specifically, we tested the following hypotheses: (1) an infection of the uterus with T. pyogenes or E. coli at $10 \pm 1$ DIM increases the risk of infection with the same pathogens and increases the risk for CE at $24 \pm$ 1 DIM, (2) an infection of the uterus with $\alpha$-hemolytic streptococci or CNS at $10 \pm 1$ DIM increases the risk of uterine infection and CE at $24 \pm 1$ DIM, (3) agreement of bacteriological findings of uterine samples is high between different laboratories, and (4) agreement of bacteriological findings is high between samples collected with CB and CS.

\section{MATERIALS AND METHODS}

\section{Study Farm}

The study was conducted between September 2009 and August 2010 on a commercial dairy farm in Brandenburg, Germany. The herd consisted of 1,162 Holstein dairy cows with an average milk production of $9,831 \mathrm{~kg}$ per lactation (4.04\% fat and $3.31 \%$ protein). Cows were managed according to the guidelines set by the International Cooperation on Harmonization of Technical Requirements for Registration of Veterinary Medicinal Products (Hellmann and Radeloff, 2000). The main barn was positioned in a northeast-southwest orientation with open ventilation and mechanical fans. Lactating cows were housed in freestall facilities with cubicles, rubber mats, and slotted floors, whereas dry cows were straw bedded. Early postpartum cows were fed a TMR consisting of $43.2 \%$ concentrate and mineral mix, $35.9 \%$ grass silage, and $20.9 \%$ corn silage $\left(\mathrm{NE}_{\mathrm{L}}=\right.$ $1.65 \mathrm{Mcal} / \mathrm{kg}$ ). Cows were milked 3 times per day (approximately at 0600,1500 , and $2200 \mathrm{~h}$ ). After calving, cows were assigned to the postpartum group until 18 to 20 DIM and examined for clinical endometritis by vaginal inspection between 21 and 27 DIM. Cows were first inseminated by an AI technician after a voluntary waiting period of 40 DIM.

\section{Study Design}

Experiment 1. The farm was visited weekly to examine all cows at $10 \pm 1$ (exam 1) and $24 \pm 1$ DIM 
(exam 2). Cows were excluded from the study if they were treated with antibiotic drugs or nonsteroidal or steroidal antiinflammatory drugs after parturition. A total of 269 cows were enrolled at exam 1.

At exam 1 and 2, body temperature was measured with a digital thermometer (Burfeind et al., 2010). Body condition score was assessed on a scale from 1 to 5 (Edmonson et al., 1989). Bacteriological samples of the endometrial surface were collected using the CB technique as described before (Kasimanickam et al., 2005). The CB (Cytobrush Plus GT; 20-mm length and 6-mm diameter; Leisegang Feinmechanik-Optik $\mathrm{GmbH}$, Berlin, Germany) was covered by a one-way catheter, enveloped with a sanitary plastic sleeve, to protect it from contamination. After cleaning the vulva with dry cellulose wipes, the instrument was inserted via the cervix into the uterine body. Inside the uterus, the sleeve was retracted and the brush pushed gently into the lumen. The endometrial sample was taken by rolling the brush while in contact with the uterine wall. The brush was retracted into the catheter to protect it during the passage through the genital tract. Finally, the brush was stored in a transport medium (Uni-Ter Amies CLR; Meus S.r.l., Piove di Sacco, Italy) for bacteriological analysis. On every fourth visit, a CB was unwrapped, dipped into sterile $\mathrm{NaCl}$, and stored in a transport medium as a negative control sample to analyze if the flora of the environment could influence the bacteriological results.

Vaginal examination was performed by vaginoscopy and assigned a vaginal discharge score (VDS) according to its distribution of clear mucus and pus. Depending on the time of examination postpartum, 2 different vaginal discharge scores were used. At the first examination, vaginal discharge was scored from 0 to 4 according to Sheldon et al. (2006): 0 = clear mucus; 1 = red-brown/ yellowish, non-smelling discharge; $2=$ mucus with pus $<50 \%$; $3=$ mucus with pus $\geq 50 \%$; and $4=$ watery, reddish-brown, fetid discharge. Cows were considered as affected with PM if diagnosed with VDS 2 to 4 . At the second examination, vaginal discharge was scored from 0 to 3 as described by LeBlanc et al. (2002): $0=$ clear mucus; 1 = predominantly clear mucus containing pus flecks; $2=$ mucopurulent mucus containing $\leq 50 \%$ pus; and $3=$ exudate containing purulent or red-brown material or foul smelling, or both. Cows were regarded as affected with $\mathrm{CE}$ when diagnosed with VDS 1 to 3.

Bacteriological samples were cultured for aerobic bacteria on sheep blood agar and enriched in brain heart infusion (BHI) medium (Oxoid Ltd., Basingstoke, Hampshire, UK) and a standard nutrition I bouillon (Merck KGaA, Darmstadt, Germany) for $48 \mathrm{~h}$ at $37^{\circ} \mathrm{C}$. The broths were streaked onto sheep blood agar plates and cultured along with the other plates for a second time $24 \mathrm{~h}$ at $37^{\circ} \mathrm{C}$. Bacteria were identified on the basis of the characteristics of the colony, Gram stain, morphology, hemolysis, biochemical profile, and other standard tests such as oxidase, catalase, and coagulase reaction and growth on MacConkey agar. Plates containing 1 or more colony-forming units were regarded as positive bacterial growth. Plates with more than 3 species or with mixed culture of moderate degree or higher were considered contaminated.

Experiment 2. Between April and August 2009, a subset of 68 cows was used to collect approximately $5 \mathrm{~mL}$ of uterine discharge at $10 \pm 1$ DIM. A disposable catheter enveloped with a sanitary plastic sleeve was inserted via the cervix into the uterus. After withdrawing the plastic sleeve, a sterile $20-\mathrm{mL}$ syringe was placed on the catheter end and fluid aspirated into the catheter. The content was transferred in a sterile plastic tube to the laboratory of the Clinic for Animal Reproduction (Freie Universität Berlin, Germany). There, tubes were shaken using a vortex for $10 \mathrm{~s}$ and 4 CS and 3 CB were immersed into the uterine discharge and stored in transport medium (Uni-Ter Amies CLR; Meus S.r.l.). One CS and $1 \mathrm{CB}$ each were sent to 3 different laboratories (laboratory A, B, and C) for bacteriological analysis. Laboratory A got 2 CS to test the intraassay repeatability of the results. All samples were labeled with consecutive numbers. Per-sample positive or negative findings of E. coli, T. pyogenes, $\alpha$-hemolytic streptococci, and CNS were compared; consequently, 272 results per laboratory and sampling method and 68 results per bacterial species were compared.

\section{Statistical Analysis}

Results of the vaginal and cytological examination, body temperature, and BCS were recorded on case report forms on farm and transferred into a spreadsheet (Excel 2003; Microsoft Corp., Redmond, WA). Animalspecific data (parity and date of parturition) and treatment and reproductive-performance data (first insemination, last insemination, number of inseminations, outcome of pregnancy diagnosis, and date of culling) were obtained from the herd management software and electronically transferred into the spreadsheet.

Reproductive performance was characterized by median days to first AI (DFAI), pregnancy rate (number of cows pregnant after first AI divided by number of cows inseminated $\times 100$ ), days to pregnancy, proportion of cows pregnant within 250 DIM (number of cows documented to be pregnant at 250 DIM divided by number of cows enrolled $\times 100$ ), mean services per pregnancy, and proportion of cows culled within 250 
DIM. Data were analyzed using SPSS for Windows (PASW Statistics 18.0; SPSS Inc., Munich, Germany).

Samples were considered bacteriologically positive when at least $T$. pyogenes, E. coli, $\alpha$-hemolytic streptococci, or CNS were found. Relative risks (RR) with $95 \%$ confidence intervals were calculated by RR analysis and binary logistic regression for vaginal discharge at $10 \pm 1$ and $24 \pm 1$ DIM, respectively and detection of bacteria at $24 \pm 1$ DIM. Bacterial isolates from the same cow at first and second examination were compared. Escherichia coli was seen as the main pathogen if T. pyogenes was not isolated. For RR analysis between $E$. coli and vaginal discharge or bacterial isolates at $24 \pm 1$ DIM, samples positive for $T$. pyogenes were excluded as described previously (Westermann et al., 2010). For analysis of RR between findings of CNS or $\alpha$-hemolytic streptococci and vaginal discharge or bacterial findings, samples positive for T. pyogenes or $E$. coli were also excluded. The effect of an intrauterine infection with the different bacterial species on days to first service and days to pregnancy were calculated with ANOVA.

Fisher's exact test was used to calculate different agreements between the sampling methods and laboratories: (1) agreements of bacteriological findings between $\mathrm{CB}$ and CS, (2) agreements of positive and negative findings overall and considering each bacterial species individually between the 3 laboratories, and (3) between both swab samples analyzed by laboratory A.

\section{RESULTS}

\section{Experiment 1}

Two hundred sixty-nine Holstein-Friesian cows were included in the study. A second sample could not be collected from 15 cows $(5.6 \%)$ because the cows were culled or sold. Hence, a total of 254 cows were eligible for final analyses.

At the first examination T. pyogenes, E. coli, $\alpha$-hemolytic streptococci, and CNS were isolated in 152 of 269 samples (56.5\%). In $39.4 \%$ of the samples $(\mathrm{n}=106)$ a mixed bacterial content or other species were isolated and $4.1 \%(\mathrm{n}=11)$ of the samples were bacteriologically negative. At the second examination, the number of bacteriologically negative findings increased to 30 (11.9\%). Trueperella pyogenes, E. coli, a-hemolytic streptococci, and CNS were isolated in 72 of $254(28.3 \%)$ samples. Trueperella pyogenes, E. coli, $\alpha$-hemolytic streptococci, and CNS were found in 27 (10.7\%), 22 (8.7\%), 18 (7.1\%), and 11 (4.3\%) samples, respectively. Mixed cultures or other species were found in $59.7 \%(\mathrm{n}=151)$ samples (Table 1$)$.

Escherichia coli at the first examination was isolated 61 times as the main pathogen: in 23 samples in monoculture, in 19 samples in combination with $\alpha$-hemolytic streptococci, and in 19 samples in combination with mixed cultures (Table 2). Fifty-seven of those cows were reexamined at the second examination. Escherichia coli in monoculture was repeatedly isolated in 8 cows and

Table 1. Intrauterine bacteriological findings in Holstein dairy cows considering 2 sampling intervals

\begin{tabular}{|c|c|c|c|c|}
\hline \multirow[b]{3}{*}{ Item } & \multicolumn{4}{|c|}{ Examination at DIM } \\
\hline & \multicolumn{2}{|c|}{$\begin{array}{c}10 \pm 1 \text { DIM } \\
(\text { total no. }=269)\end{array}$} & \multicolumn{2}{|c|}{$\begin{array}{c}24 \pm 1 \text { DIM } \\
(\text { total no. }=254)\end{array}$} \\
\hline & $\mathrm{n}$ & $\%$ & $\mathrm{n}$ & $\%$ \\
\hline Bacteriological findings & 152 & 56.5 & 72 & 28.5 \\
\hline Trueperella pyogenes in monoculture & 4 & & 13 & \\
\hline With Escherichia coli & 5 & & 3 & \\
\hline With CNS or $\alpha$-hemolytic streptococci & 7 & & 1 & \\
\hline With mixed or other flora & 9 & & 10 & \\
\hline Total & 25 & 9.3 & 27 & 10.6 \\
\hline E. coli in monoculture & 23 & & 1 & \\
\hline With CNS or $\alpha$-hemolytic streptococci & 20 & & 2 & \\
\hline With mixed or other flora & 18 & & 15 & \\
\hline Total $^{1}$ & 66 & 24.5 & 22 & 8.7 \\
\hline$\alpha$-Hemolytic streptococci in monoculture & 32 & & 11 & \\
\hline With mixed or other flora & 26 & & 5 & \\
\hline Total $^{1}$ & 84 & 31.2 & 18 & 7.1 \\
\hline CNS in monoculture & 3 & & 4 & \\
\hline With mixed or other flora & 5 & & 6 & \\
\hline Total $^{1}$ & 13 & 4.8 & 11 & 4.3 \\
\hline
\end{tabular}

${ }^{1}$ Combinations with bacteria that are listed before are not shown. Therefore, numbers of isolates do not sum up to the total number of positive samples for this species. 
Table 2. Relationships of bacteriological findings between $10 \pm 1$ and $24 \pm 1$ DIM

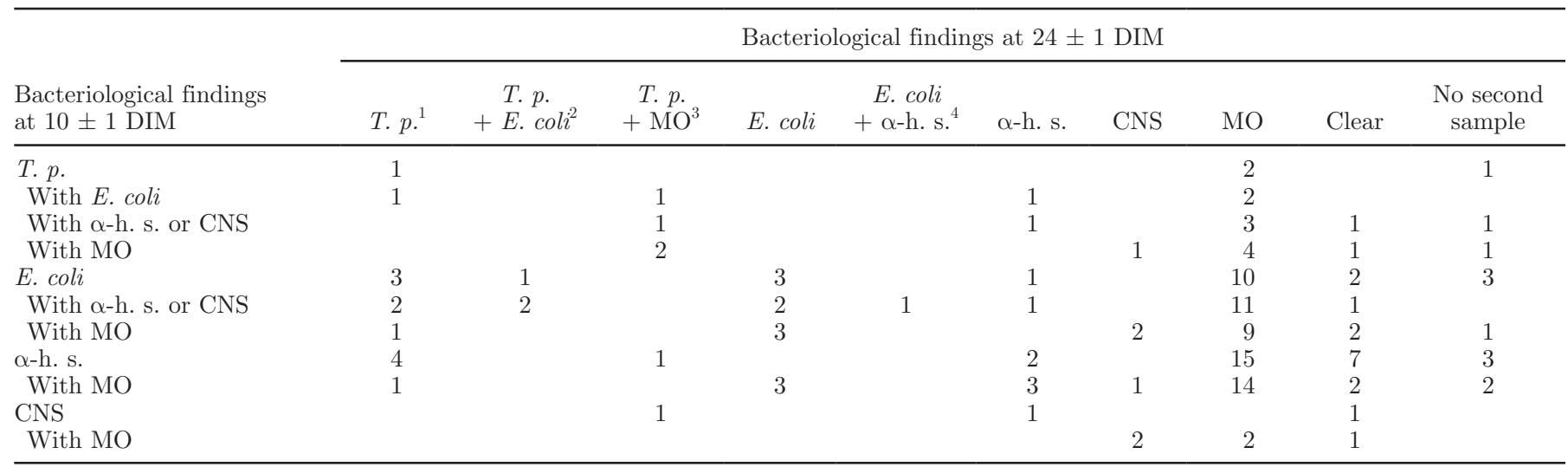

${ }^{1}$ T. p. $=$ Trueperella pyogenes.

${ }^{2}$ E. coli $=$ Escherichia coli .

${ }^{3} \mathrm{MO}=$ mixed flora or other bacteria.

${ }^{4} \alpha$-h. s. $=\alpha$-hemolytic streptococci.

in 1 cow in combination with $\alpha$-hemolytic streptococci. A new infection with $T$. pyogenes in monoculture or in combination with $E$. coli occurred in 9 cows.

Trueperella pyogenes was isolated in monoculture, in combination with E. coli, and in combination with $\alpha$-hemolytic streptococci in 4,5 , and 7 of the 25 samples, respectively. At the second examination, 22 cows positive for $T$. pyogenes at exam 1 were reexamined and T. pyogenes was found in 6 cows.

Coagulase-negative staphylococci and $\alpha$-hemolytic streptococci in monoculture were isolated in 58 and 8 cows, respectively. At the second examination T. pyogenes and E. coli were found in 7 and 3 cows, respectively (Table 2).

Cows infected with $T$. pyogenes had greater risk to be diagnosed with abnormal vaginal discharge at first $(\mathrm{RR}=2.4, P<0.001)$ and second examination (RR $=2.4, P<0.001)$ than cows without an infection of T. pyogenes. The presence of $\alpha$-hemolytic streptococci increased the risk of abnormal vaginal discharge at the first examination $(\mathrm{RR}=2.0 ; P<0.001)$. Cows infected with T. pyogenes or E. coli at the first examination had higher risks $(P<0.05)$ to be diagnosed with VDS 1 to 3 two weeks later (Table 3 ). For those cows, the relative risk to be diagnosed with VDS 2 or 3 at the second examination was also higher $(T$. pyogenes $\mathrm{RR}=$ $2.7, P<0.001 ; E$. coli $\mathrm{RR}=1.9, P<0.01)$. Cows with an intrauterine infection of $T$. pyogenes or $E$. coli at first examination were at higher risk to be rediagnosed with the same bacterial species at the second examination $(T$. pyogenes $\mathrm{RR}=2.9$, E. coli $\mathrm{RR}=3.7$; Table $3)$. When $\alpha$-hemolytic streptococci were present at the first examination, RR for an infection with identical bacterial species, T. pyogenes or E. coli (Table 3) at the second examination did not increase. Positive findings of CNS at exam 1 only increased the risk to be rediagnosed with the same bacterial species at exam 2 .

Median DFAI for cows without E. coli or T. pyogenes, with E. coli, and with T. pyogenes were 59, 70 and 69, respectively (Table 4). Cows with E. coli at first or T. pyogenes at second examination had greater DFAI than cows positive for T. pyogenes, $\alpha$-hemolytic strep-

Table 3. Relative risks with $95 \%$ CI of abnormal vaginal discharge and presence of identical bacterial species at $24 \pm 1$ DIM if the cow was positive for 1 of the 4 bacterial species at $10 \pm 1$ DIM

\begin{tabular}{|c|c|c|c|c|}
\hline \multirow{3}{*}{$\begin{array}{l}\text { Pathogen identified at } \\
10 \pm 1 \text { DIM }\end{array}$} & \multicolumn{4}{|c|}{$24 \pm 1 \mathrm{DIM}$} \\
\hline & \multicolumn{2}{|c|}{ Abnormal vaginal discharge } & \multicolumn{2}{|c|}{ Identical bacterial species } \\
\hline & Relative risk & $95 \% \mathrm{CI}$ & Relative risk & $95 \%$ CI \\
\hline Escherichia coli & $1.7^{* *}$ & $1.28-2.25$ & $3.7^{* *}$ & $1.67-8.18$ \\
\hline Trueperella pyogenes & $1.7^{*}$ & $1.20-2.37$ & $2.9^{*}$ & $1.29-6.38$ \\
\hline$\alpha$-Hemolytic streptococci & 1.4 & $1.02-1.84$ & 1.8 & $0.74-4.40$ \\
\hline CNS & 0.3 & $0.05-1.87$ & $10.3^{*}$ & $2.44-43.14$ \\
\hline
\end{tabular}

${ }^{*} P<0.05 ;{ }^{* *} P<0.01$. 
Table 4. Descriptive reproductive performance traits of 254 cows examined at $10 \pm 1$ DIM

\begin{tabular}{|c|c|c|c|}
\hline \multirow[b]{2}{*}{ Trait } & \multicolumn{3}{|c|}{ Bacteriological findings at $10 \pm 1 \mathrm{DIM}$} \\
\hline & Negative $^{1}$ & Escherichia coli ${ }^{2}$ & Trueperella pyogenes ${ }^{3}$ \\
\hline Number of cows & 174 & 57 & 23 \\
\hline Cows inseminated (\%) & 92.5 & 91.2 & 91.3 \\
\hline Mean services per pregnancy & 2.7 & 2.5 & 3.4 \\
\hline Median days to first AI & 59 & $70^{\mathrm{a}}$ & 69 \\
\hline Pregnancy rate (\%) & 19.5 & 19.3 & 13.0 \\
\hline Median days to pregnancy & 96 & 108 & $139^{\mathrm{b}}$ \\
\hline Cows pregnant $(\%)$ & 71.8 & 64.9 & 65.2 \\
\hline Cows culled (\%) & 5.7 & $15.8^{\mathrm{b}}$ & 4.3 \\
\hline
\end{tabular}

tococci, or CNS at $10 \pm 1$ DIM $(P<0.001)$ or $E$. coli, $\alpha$-hemolytic streptococci, or CNS at $24 \pm 1$ DIM $(P$ $<0.001$ ). Median days to pregnancy were significantly higher for cows with $T$. pyogenes at first examination compared with cows with E. coli, $\alpha$-hemolytic streptococci, or CNS at $10 \pm 1$ DIM $(P<0.05)$. More cows were culled when identified with $E$. coli at $10 \pm 1$ DIM (Table 4) compared with cows with $T$. pyogenes or cows without E. coli or T. pyogenes.

\section{Experiment 2}

Agreements of bacteriological results of laboratory $\mathrm{A}+\mathrm{B}$ and $\mathrm{A}+\mathrm{C}$ were highly significant for $\mathrm{CB}$ and CS. Discrepancies between laboratory A + B and A $+\mathrm{C}$ were found when distinct bacterial species were considered. Agreement for E. coli was high (Table 5). Agreements for T. pyogenes and $\alpha$-hemolytic streptococci were not significant of laboratory A + C from CS and CB, respectively (Table 5). Interlaboratory agreements between CB and CS were significant for all 3 laboratories as was intralaboratory repeatability for laboratory A.

\section{DISCUSSION}

\section{Experiment 1}

The objective of the present study was to examine the bacterial content in the uterus of postpartum dairy cows at $10 \pm 1 \mathrm{DIM}$ and $24 \pm 1$ DIM and their relationship with $\mathrm{PM}, \mathrm{CE}$, and subsequent reproductive performance. Furthermore, agreement of different laboratories and collection tools (i.e., CB and CS) were studied.

Overall, bacterial species isolated in experiment 1 were similar to those of previous reports (Williams et al., 2005; Földi et al., 2006). Samples were not cultured for anaerobe uterine pathogens such as F. necrophorum and P. melaninogenica. Hence, their effects cannot be discussed.

It has been shown that bacterial contamination of the uterus decreases with increasing days postpartum (Elliott et al., 1968). In our study, this observation could be confirmed for E. coli and $\alpha$-hemolytic streptococci. Escherichia coli and T. pyogenes are relevant uterine pathogens and most frequently isolated (Huszenicza et al., 1999; Sheldon and Dobson, 2004). Their pathogenic

Table 5. Number of positive $(++)$ and negative $(-)$ agreements from 68 samples and disagreements $(+-)$ of each bacterial species for cytobrushes and cotton swabs from laboratory A + B and A + C

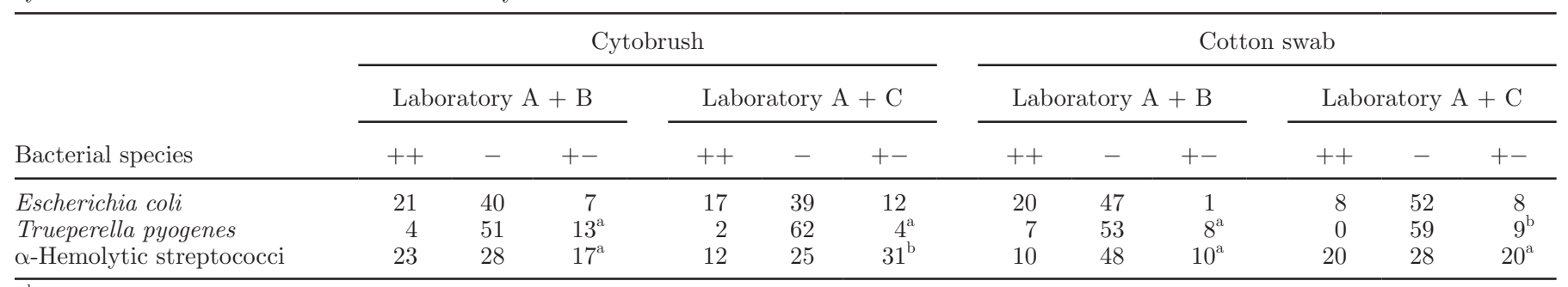

${ }^{a, b}$ Values within a column with different superscripts differ $(P<0.01)$. 
potential was the focus of various studies, describing their pathomechanism, as well as effect on mucus character, ovarian activity, and fertility (Huszenicza et al., 1999; Williams et al., 2005; Sheldon et al., 2010).

Cows enrolled in this study did not show any signs of systemic illness and remained untreated throughout the whole observation period. Prevalence rates for E. coli were 24.5 and $8.7 \%$ at first and second examination, respectively. Fifty-nine percent of samples (36/61) positive with E. coli showed high growth density (HGD; i.e., $>100$ colonies per plate) according to Williams et al. (2005). Infections with E. coli at $10 \pm$ 1 DIM increased considerably the risk for persistent infections, CE, or new infections with T. pyogenes, despite the observation that 49 of 61 cows cleared their infection with $E$. coli between both examinations. The high risk for persistent infections can be explained by $E$. coli strains specifically pathogenic for the uterus (Sheldon et al., 2010). It has also been assumed that an infection with $E$. coli increases the susceptibility of the endometrium to an infection with T. pyogenes (Williams et al., 2007), induced by a functional depression of neutrophils (Zerbe et al., 2001). Our data support this assumption, as T. pyogenes appeared as a consequence of an infection with $E$. $\operatorname{coli}(\mathrm{RR}=1.8, P$ $>0.1$ ) but not vice versa.

It is well documented that the presence and character of vaginal discharge has diagnostic value to identify cows with clinical endometritis (LeBlanc et al., 2002; Williams et al., 2005; Sheldon et al., 2006). We examined the relationship between bacteriological findings in the uterus and vaginal discharge at the same day and 2 wk later to provide further evidence for the relevance of VDS. We did not find an effect of $E$. coli on vaginal discharge on the same examination day as described previously (Williams et al., 2005; Westermann et al., 2010). However, the higher risk for abnormal vaginal discharge 2 wk after an infection with $E$. coli has not been described yet. We speculate that this was due to the pathogenic characteristics of $E$. coli to predispose the endometrium to other bacteria (Williams et al., 2007). This assumption was confirmed by the prevalence of T. pyogenes, which was higher in cows that had been infected with $E$. coli at $10 \pm 1$ DIM. To describe relationships between bacteria and vaginal discharge, we considered the definition of LeBlanc et al. (2002) for CE. They did not find an association between mucus with flecks of pus and reduced pregnancy rate and, therefore, excluded cows with only slight alterations from the case definition. Clinical endometritis was defined as the presence of purulent or foul discharge between 20 and 33 DIM or mucopurulent discharge after 26 DIM. In our study, we found a higher risk for
VDS 1 to 3 in cows infected with $E$. coli at $10 \pm 1$ DIM compared with cows not infected with $E$. coli. When we excluded VDS 1, as suggested, the risk for VDS 2 or 3 and, consequently, the risk for $\mathrm{CE}$ at exam 2 increased. The higher numbers of cows culled and greater DFAI for animals infected with $E$. coli compared with cows infected with $T$. pyogenes or without infection of $E$. coli or T. pyogenes can be explained by the damage of the endometrium as postulated previously (Zerbe et al., 2001).

Huszenicza et al. (1999) compared prevalence of bacterial isolates from cows with acute puerperal (endo) metritis, which were treated after the first examination with intrauterine antibiotic drugs (i.e., oxytetracycline), with the prevalence in healthy cows. They observed higher prevalence rates of $T$. pyogenes in cows with acute puerperal (endo)metritis compared with healthy cows and a negative association between long-term presence of $T$. pyogenes and reproductive performance. In our study, prevalence of $T$. pyogenes and percentage of samples with HGD was similar at $10 \pm 1$ (HGD of $20 / 25 ; 80.0 \%$ ) and $24 \pm 1$ DIM (HGD of $20 / 27$; $74.1 \%)$. However, not all cows infected at exam 1 were rediagnosed at exam 2, but the risk for a persistent infection with T. pyogenes was significant. Severe endometrial lesions caused by T. pyogenes (Bonnett et al., 1991; Azawi et al., 2008) and increased susceptibility of the endometrium for this pathogen due to previous E. coli infections (Zerbe et al., 2001; Williams et al., 2007) may contribute to the persistent infection seen in our study. The association between $T$. pyogenes and abnormal vaginal discharge demonstrated in our data confirms earlier reports (Huszenicza et al., 1999; Williams et al., 2005; Westermann et al., 2010). The high risk for abnormal vaginal discharge regardless of the examination day and the high risk of persistent infection in cows infected with $T$. pyogenes $10 \pm 1$ DIM explain the high risk for VDS 1 to 3 at $24 \pm 1$ DIM. After exclusion of mild discharge, the risk increased for VDS 2 or 3, indicative for CE, at $24 \pm 1$ DIM after an infection with T. pyogenes at $10 \pm 1$. Days to pregnancy in our study were greater for cows diagnosed with $T$. pyogenes at exam 1 compared with cows infected with $E$. coli or without infection of $E$. coli or T. pyogenes. Cows with T. pyogenes at exam 2 had significantly higher DFAI than cows without T. pyogenes. Both effects on reproductive performance have been described for $T$. pyogenes (Williams et al., 2005) and, in general, for cows with CE (LeBlanc et al., 2002). This, however, is the first report considering infections at specified DIM intervals. In recent studies, uterine samples were taken during a relatively long window (20 to 33 DIM), which might have biased the results. 
Coagulase-negative staphylococci and $\alpha$-hemolytic streptococci were included in our experiment because prevalence has been reported to be high in the uterus (Williams et al., 2005; Sheldon et al., 2009a). In the study of Huszenicza et al. (1999), prevalence of staphylococci and streptococci at 10 DIM was higher in cows without uterine complications compared with cows with acute puerperal (endo)metritis. These bacteria have been considered as normal uterine flora (Huszenicza et al., 1999) or opportunists (Williams et al., 2005), respectively. In studies investigating risk factors for mastitis pathogenicity of CNS varies from being protective to being the cause of subclinical and clinical mastitis (De Vliegher et al., 2012). Furthermore, a significantly lower risk for abnormal vaginal discharge or no association at all between fetid vaginal mucus odor and opportunist contaminants was reported (Williams et al., 2005). We examined the effect of $\alpha$-hemolytic streptococci and CNS on vaginal mucus and on aerobic bacterial prevalence at 2 distinct times postpartum. Coagulase-negative staphylococci were isolated in only 8 of 269 samples at exam 1. Due to the low prevalence, a conclusion about their pathogenic potential is not possible. The presence of $\alpha$-hemolytic streptococci was only associated with an increased risk for abnormal vaginal discharge at exam 1 . We did not reconfirm this relationship at $24 \pm 1$ DIM as described by Williams et al. (2005). Their and our data are inconclusive regarding their role as opportunists. Overall, data do not provide consistent evidence for a preventive effect of $\alpha$-hemolytic streptococci.

Our first hypothesis, that an infection of the uterus with E. coli or T. pyogenes increases the risk for a persistent infection with identical bacterial species and CE can be confirmed. As described earlier, the terminology CE may not be fully appropriate, as vaginal discharge is not an accurate descriptor for the location (vagina, cervix, or uterus) of the inflammation (Dubuc et al., 2010a,b). The second hypothesis can neither be proven nor rejected because of insufficient animals with CNS and no significant risk for E. coli or T. pyogenes resulting from an infection with $\alpha$-hemolytic streptococci.

Other bacterial species or mixed cultures with more than 3 bacterial species were isolated at first and second examination in 39.4 and $59.7 \%$ of examined cows, respectively. We speculate that contamination with environmental bacteria occurred during sampling or rolling the $\mathrm{CB}$ on the microscopic slide. None of the 11 negative control samples, however, showed a contamination with E. coli, T. pyogenes, or CNS. Mixed cultures were isolated in 4 samples, 1 of which with 1 Acinetobacter species and 1 sample that was positive for $\alpha$-hemolytic streptococci.

\section{Experiment 2}

To determine interlaboratory repeatability of bacteriological findings, samples (e.g., agar slants, water, and waste) with known types of bacteria and colonyforming units were used in previous studies (Wallmann et al., 2006; Kalbe et al., 2007). In our samples, the types and load of bacterial species were unknown and a gold standard did not exist. Our objective was to test the agreement of the bacteriological examinations under field conditions for uterine samples. The agreement between $\mathrm{CB}$ and $\mathrm{CS}$ between the laboratories was good. Laboratory A and B showed the highest agreement for CB (234 of 272) and CS (252 of 272). Differences between laboratory $\mathrm{A}$ and $\mathrm{C}$ might be due to different storage conditions of the samples before culture. Samples for laboratory A and B were stored for approximately $14 \mathrm{~h}$ at $+7^{\circ} \mathrm{C}$ until cultivation. Samples for laboratory $\mathrm{C}$ were shipped unchilled for the same time. Additionally, variations in culture conditions and differentiation procedures of the laboratories may have influenced the bacteriological results. For E. coli, agreements of bacteriological results from 68 samples were high, regardless of laboratory or sampling method (CB: laboratory A + B: $61 / 68$, laboratory A + C: 56/68; CS: laboratory A + B: 67/68, laboratory A + C: 60/68). The agreements of laboratory $\mathrm{A}$ and $\mathrm{C}$ for $T$. pyogenes from CB (59 of 68) and $\alpha$-hemolytic streptococci from CS (37 of 68) were not significant (Table 5). We assume that the lack of cooling during the transport to laboratory $\mathrm{C}$ might have affected agreement. It is known that temperature, time, and type of swab (Roelofsen et al., 1999), media (Yrios et al., 1975), and transport system (Rishmawi et al., 2007; Stoner et al., 2008; Musser and Gonzalez, 2011) affect viability and stability of microorganisms. Effects of our transport medium on our 4 target pathogens have not been examined yet. Escherichia coli strains were stable at $4^{\circ} \mathrm{C}$ up to 96 $\mathrm{h}$, but concentrations increased at room temperature $\left(24^{\circ} \mathrm{C}\right)$ at $24 \mathrm{~h}$ (Rishmawi et al., 2007; Stoner et al., 2008). Additional storage at $-80^{\circ} \mathrm{C}$ for $40 \mathrm{~d}$ or $1 \mathrm{~h}$ at room temperature had no significant effect on growth scores of E. coli (Musser and Gonzalez, 2011). These results indicate that $E$. coli can be isolated more easily from unchilled than from cooled samples but increase the risk of overgrowing fastidious organisms (Rishmawi et al., 2007).

Recent studies describing uterine bacterial contents have used guarded CS or biopsy methods (Sheldon et al., 2002; Williams et al., 2005; Petit et al., 2009). To diagnose subclinical endometritis, the $\mathrm{CB}$ technique has been described and validated (Kasimanickam et al., 2005). More recently this technique has been used 
to harvest endometrial cells and bacteria from the uterine lumen simultaneously (Westermann et al., 2010). The advantage of this method is to obtain information about the inflammatory and bacteriological status with only one sampling procedure. Admittedly, the rate of bacteriologically positive samples from CS was higher, but the agreement between both sampling methods was high for all laboratories $(P<0.001)$. Because a gold standard does not exist, it is impossible to prove which results are more accurate. Overall, we conclude that the results from $\mathrm{CB}$ are meaningful for bacteriological analysis and consider using $\mathrm{CB}$ a valuable technique to generate information about infectious and inflammatory properties in the endometrium with 1 sample.

\section{CONCLUSIONS}

Our results demonstrate that cows infected with $E$. coli or T. pyogenes at $10 \pm 1$ DIM are prone to persistent infections with the same bacterial species and abnormal vaginal discharge 2 wk later. Accordingly, the risk to be diagnosed with clinical endometritis increases as well. Contrary to our second hypothesis, we did not find relationships between $\alpha$-hemolytic streptococci or CNS and infections with the same bacterial species, E. coli, T. pyogenes, or abnormal vaginal discharge at the second examination, respectively. Cows positive for $\alpha$-hemolytic streptococci had a higher risk for abnormal vaginal discharge at $10 \pm 1$ DIM. Further research is warranted to elucidate the role of CNS and $\alpha$-hemolytic streptococci as opportunistic or pathogenic microorganisms. For pathogens examined, laboratories showed high agreements for $\mathrm{CB}$ and CS. The agreements between $\mathrm{CB}$ and CS of each laboratory and intralaboratory results were highly significant.

\section{ACKNOWLEDGMENTS}

The authors thank the owners and staff of the dairy farm for their superb cooperation and all practitioners involved in the trial for their valuable assistance.

\section{REFERENCES}

Azawi, O. I., S. N. Omran, and J. J. Hadad. 2008. A study of endometritis causing repeat breeding of cycling Iraqi buffalo cows. Reprod. Domest. Anim. 43:735-743.

Bondurant, R. H. 1999. Inflammation in the bovine female reproductive tract. J. Anim. Sci. 77(Suppl. 2):101-110.

Bonnett, B. N., S. W. Martin, V. P. Gannon, R. B. Miller, and W. G. Etherington. 1991. Endometrial biopsy in Holstein-Friesian dairy cows. III. Bacteriological analysis and correlations with histological findings. Can. J. Vet. Res. 55:168-173.

Burfeind, O., M. A. von Keyserlingk, D. M. Weary, D. M. Veira, and W. Heuwieser. 2010. Short communication: Repeatability of measures of rectal temperature in dairy cows. J. Dairy Sci. 93:624627.
De Vliegher, S., L. K. Fox, S. Piepers, S. McDougall, and H. W. Barkema. 2012. Invited review: Mastitis in dairy heifers: Nature of the disease, potential impact, prevention, and control. J. Dairy Sci. 95:1025-1040

Dubuc, J., T. F. Duffield, K. E. Leslie, J. S. Walton, and S. J. LeBlanc. 2010a. Definitions and diagnosis of postpartum endometritis in dairy cows. J. Dairy Sci. 93:5225-5233.

Dubuc, J., T. F. Duffield, K. E. Leslie, J. S. Walton, and S. J. LeBlanc. 2010b. Risk factors for postpartum uterine diseases in dairy cows. J. Dairy Sci. 93:5764-5771.

Edmonson, A. J., I. J. Lean, L. D. Weaver, T. Farver, and G. Webster. 1989. A body condition scoring chart for Holstein dairy cows. J. Dairy Sci. 72:68-78.

Elliott, L., K. J. McMahon, H. T. Gier, and G. B. Marion. 1968. Uterus of the cow after parturition: Bacterial content. Am. J. Vet. Res. 29:77-81.

Földi, J., M. Kulcsár, A. Pécsi, B. Huyghe, C. de Sa, J. A. Lohuis, P. Cox, and G. Huszenicza. 2006. Bacterial complications of postpartum uterine involution in cattle. Anim. Reprod. Sci. 96:265-281.

Hellmann, K., and I. Radeloff. 2000. International Cooperation on Harmonization of Technical Requirements for Registration of Veterinary Medicinal Products. VICH, Brussels, Belgium.

Huszenicza, G., M. Fodor, M. Gacs, M. Kulcsar, M. J. W. Dohmen, M. Vamos, L. Porkolab, T. Kegl, J. Bartyik, J. A. C. M. Lohuis, S. Janosi, and G. Szita. 1999. Uterine bacteriology, resumption of cyclic ovarian activity and fertility in postpartum cows kept in large-scale dairy herds. Reprod. Domest. Anim. 34:237-245.

Kalbe, U., W. Berger, F.-G. Simon, J. Eckardt, and G. Christoph. 2007. Results of interlaboratory comparisons of column percolation tests. J. Hazard. Mater. 148:714-720.

Kaneko, K., and S. Kawakami. 2008. Influence of experimental intrauterine infusion of Arcanobacterium pyogenes solution on ovarian activity in cycling cows. J. Vet. Med. Sci. 70:77-83.

Kasimanickam, R., T. F. Duffield, R. A. Foster, C. J. Gartley, K. E. Leslie, J. S. Walton, and W. H. Johnson. 2005. A comparison of the cytobrush and uterine lavage techniques to evaluate endometrial cytology in clinically normal postpartum dairy cows. Can. Vet. J. 46:255-259.

Kaufmann, T. B., M. Drillich, B. A. Tenhagen, D. Forderung, and W. Heuwieser. 2009. Prevalence of bovine subclinical endometritis $4 \mathrm{~h}$ after insemination and its effects on first service conception rate. Theriogenology 71:385-391.

Koonings, P. P., K. Dickinson, G. d'Ablaing III, and J. B. Schlaerth. 1992. A randomized clinical trial comparing the cytobrush and cotton swab for Papanicolaou smears. Obstet. Gynecol. 80:241-245.

LeBlanc, S. J., T. F. Duffield, K. E. Leslie, K. G. Bateman, G. P. Keefe, J. S. Walton, and W. H. Johnson. 2002. Defining and diagnosing postpartum clinical endometritis and its impact on reproductive performance in dairy cows. J. Dairy Sci. 85:2223-2236.

Lewis, G. S. 1997. Uterine health and disorders. J. Dairy Sci. 80:984994

Miller, A. N., E. J. Williams, K. Sibley, S. Herath, E. A. Lane, J. Fishwick, D. M. Nash, A. N. Rycroft, H. Dobson, C. E. Bryant, and I. M. Sheldon. 2007. The effects of Arcanobacterium pyogenes on endometrial function in vitro, and on uterine and ovarian function in vivo. Theriogenology 68:972-980.

Musser, J. M., and R. Gonzalez. 2011. Efficacy of an anaerobic swab transport system to maintain aerobic and anaerobic microorganism viability after storage at $-80^{\circ} \mathrm{C}$. J. Vet. Diagn. Invest. 23:95-99.

Petit, T., J. Spergser, R. Rosengarten, and J. Aurich. 2009. Prevalence of potentially pathogenic bacteria as genital pathogens in dairy cattle. Reprod. Domest. Anim. 44:88-91.

Plöntzke, J., L. V. Madoz, R. L. De la Sota, W. Heuwieser, and M. Drillich. 2011. Prevalence of clinical endometritis and its impact on reproductive performance in grazing dairy cattle in Argentina. Reprod. Domest. Anim. 46:520-526.

Potter, T. J., J. Guitian, J. Fishwick, P. J. Gordon, and I. M. Sheldon. 2010. Risk factors for clinical endometritis in postpartum dairy cattle. Theriogenology 74:127-134.

Rishmawi, N., R. Ghneim, R. Kattan, R. Ghneim, M. Zoughbi, A. Abu-Diab, S. Turkuman, R. Dauodi, I. Shomali, A. El-Razeq Issa, 
I. Siriani, H. Marzouka, I. Schmid, and M. Y. Hindiyeh. 2007. Survival of fastidious and nonfastidious aerobic bacteria in three bacterial transport swab systems. J. Clin. Microbiol. 45:1278-1283.

Roelofsen, E., M. van Leeuwen, G. J. Meijer-Severs, M. H. Wilkinson, and J. E. Degener. 1999. Evaluation of the effects of storage in two different swab fabrics and under three different transport conditions on recovery of aerobic and anaerobic bacteria. J. Clin. Microbiol. 37:3041-3043.

Sheldon, I. M., J. Cronin, L. Goetze, G. Donofrio, and H. J. Schuberth. 2009a. Defining postpartum uterine disease and the mechanisms of infection and immunity in the female reproductive tract in cattle. Biol. Reprod. 81:1025-1032.

Sheldon, I. M., and H. Dobson. 2004. Postpartum uterine health in cattle. Anim. Reprod. Sci. 82-83:295-306.

Sheldon, I. M., G. S. Lewis, S. LeBlanc, and R. O. Gilbert. 2006. Defining postpartum uterine disease in cattle. Theriogenology 65:1516-1530

Sheldon, I. M., D. E. Noakes, A. N. Rycroft, D. U. Pfeiffer, and H. Dobson. 2002. Influence of uterine bacterial contamination after parturition on ovarian dominant follicle selection and follicle growth and function in cattle. Reproduction 123:837-845.

Sheldon, I. M., S. B. Price, J. Cronin, R. O. Gilbert, and J. E. Gadsby. 2009b. Mechanisms of infertility associated with clinical and subclinical endometritis in high producing dairy cattle. Reprod. Domest. Anim. 44(Suppl. 3):1-9.

Sheldon, I. M., A. N. Rycroft, B. Dogan, M. Craven, J. J. Bromfield, A. Chandler, M. H. Roberts, S. B. Price, R. O. Gilbert, and K. W. Simpson. 2010. Specific strains of Escherichia coli are pathogenic for the endometrium of cattle and cause pelvic inflammatory disease in cattle and mice. PLoS ONE 5:e9192.

Sheldon, I. M., E. J. Williams, A. N. Miller, D. M. Nash, and S. Herath. 2008. Uterine diseases in cattle after parturition. Vet. J. $176: 115-121$
Stoner, K. A., L. K. Rabe, M. N. Austin, L. A. Meyn, and S. L. Hillier. 2008. Quantitative survival of aerobic and anaerobic microorganisms in Port-A-Cul and Copan transport systems. J. Clin. Microbiol. 46:2739-2744.

Wallmann, J., A. Böttner, L. Goossens, H. M. Hafez, K. Hartmann, H. Kaspar, C. Kehrenberg, M. Kietzmann, D. Klarmann, G. Klein, P. Krabisch, T. Kühn, G. Luhofer, A. Richter, B. Schulz, S. Schwarz, C. Sigge, W. Traeder, K.-H. Waldmann, C. Werckenthin, and E. Zschiesche. 2006. Results of an interlaboratory test on antimicrobial susceptibility testing of bacteria from animals by broth microdilution. Int. J. Antimicrob. Agents 27:482-490.

Westermann, S., M. Drillich, T. B. Kaufmann, L. V. Madoz, and W. Heuwieser. 2010. A clinical approach to determine false positive findings of clinical endometritis by vaginoscopy by the use of uterine bacteriology and cytology in dairy cows. Theriogenology 74:1248-1255.

Williams, E. J., D. P. Fischer, D. E. Noakes, G. C. England, A. Rycroft, H. Dobson, and I. M. Sheldon. 2007. The relationship between uterine pathogen growth density and ovarian function in the postpartum dairy cow. Theriogenology 68:549-559.

Williams, E. J., D. P. Fischer, D. U. Pfeiffer, G. C. England, D. E. Noakes, H. Dobson, and I. M. Sheldon. 2005. Clinical evaluation of postpartum vaginal mucus reflects uterine bacterial infection and the immune response in cattle. Theriogenology 63:102-117.

Yrios, J. W., E. Balish, A. Helstad, C. Field, and S. Inhorn. 1975. Survival of anaerobic and aerobic bacteria on cotton swabs in three transport systems. J. Clin. Microbiol. 1:196-200.

Zerbe, H., C. Oßadnik, W. Leibold, and H. J. Schuberth. 2001. Influence of Escherichia coli and Arcanobacterium pyogenes isolated from bovine puerperal uteri on phenotypic and functional properties of neutrophils. Vet. Microbiol. 79:351-365. 